\title{
Research on the Way of Infiltrating Life Education in School Physical Education
}

\author{
Changzhi Jia, Fan Zhang* \\ Department of Police Skills and Tactics, Nanjing Forest Police College, Nanjing 210023, China \\ * Corresponding author
}

Keywords: Physical education; life education; humanization; school education.

Abstract. Life education and school physical education have high homogeneity in educational connotation. By clarifying the relationship between school physical education and life education, the research reveals the consistency between school physical education and life education and explores the positive role of school physical education in life education. Through school physical education, students can learn to understand the meaning and value of life in the practice of sports, so as to realize the purpose of life education that respects life, show reverence for life and loves life.

\section{Introduction}

The concept of life education was first proposed in the 1960s. At the beginning of the 21st century, life education, based on the principle of "respecting life and caring for life", was not only a reflection on the essence of education, but also an extraction of educational purposes. From the very beginning of its birth, school physical education has devoted itself to improving the quality of life and the sustainable development of the human body. However, there was a huge gap between the "educational ideal" of school physical education for life education and the realistic dilemma of physical education. The expression of life education on life integrity, quality of life, freedom and autonomy of life appears in the real world as a multi-dimensional display of natural life, spiritual life and social life, respectively corresponding to the three-dimensional view of health, i.e. physical health, psychological health and social adaptation. Problems in any of the three dimensions of life and health will lead to the absence of complete life, the disability or even death of natural attributes, maladaptation of social attributes, and unhealthy mental attributes. The results of a national survey of suicides among college students in ordinary universities (2005-2015) show that the number of valid cases of suicide in 10 years was 203, The number of valid suicide cases in 10 years was 203, of which 5\% committing suicide due to physical problems, $7 \%$ due to psychological problems, $4 \%$ due to work, $12 \%$ due to learning, $8 \%$ due to love affair, and $2 \%$ due to interpersonal problems. This reflected the misunderstanding of college students' awareness, reverence, respect, kindness and love for life, the seriousness of the lack of life education in school education, and the importance as well as urgency of carrying out life education.

In 2016, Opinions of General Office of the State Council on Strengthening School Physical Education to Promote the Overall Development of Students' Physical and Mental Health clearly proposed to "improve the quality of physical education in an all-round way and improve students' personality quality" and to spread "scientific views on education, talents and health". This paper reveals the significance of life education by studying the essence and connotation of life education, studies the role of school physical education in the implementation of life education, and explores effective ways to implement life education, so that students can receive effective life education at the school education stage and realize the integration of school physical education curriculum reform and life education through the effective combination of school physical education and life education.

\section{Connotation Analysis of Life Education Involved in School Physical Education}

\subsection{Homogeneity of life education and school physical education.}

As a purposeful and planned social activity to cultivate people, education should be based on the promotion of individual development and be guided by the promotion of social progress. Education should 
focus on educating people so that students can become complete persons in the true sense. This is the original intention and essence of education. Education is the need of life. Education makes life a brand new. Therefore, life education is the essence of education.

Life education is to make students realize the limitation and uniqueness of life, and that any viewpoint and behavior that is indifferent to the value of life is wrong [1]. According to the natural, spiritual and social dimensions of life, the basic law of social development and the logic starting point of history for social development contradiction, the content of life education should consist of three dimensions that are cherishing life education, life development education and self-actualization education. Teachers should improve students' perception of life, enable students to have positive attitudes towards life, enrich students' feelings towards life, raise the awareness of individuals' responsibility for life, and form the awareness of striving to cherish, respect and protect life. Through the contents and forms of education such as social adaptability, interpersonal relationship handling, resistance to life setbacks and career development planning, the individual's socialization level can be improved, so as to enhance the individual's social adaptability. At the same time, students can clearly understand the purpose and value of life existence and continuously develop as well as perfect themselves in the process of realizing the purpose.

\subsection{Internal consistency between school physical education and life education.}

Physical education is the subordinate concept of education. School physical education is one of the important forms of physical education, carrying the functions of education and physical education. There is internal consistency between the meaning and value of physical education and life education from content to form. This internal consistency and the operability of physical education have positive practical significance for expanding the content and form of life education. The consistency of the triple attributes of school physical education and life education shows that the people's life is a complete living body composed of three dimensions that are natural life, spiritual life and social life. School physical education is a science that studies and reveals the law of cultivating people in school physical education. It is centered on cultivating people of all-round development and emphasizes all-round cultivation of students' cognition, skills, body, psychology and social adaptation.

\subsection{Content consistency between school physical education and life education.}

The school physical education contains educational content with the core values of excellence, friendship and respect advocated by the Olympic movement [2]. If students want to cherish life, they must first truly understand the existence of life and truly perceive the existence of life. In the process of school physical education, students can truly learn the existence of life by experiencing a series of physiological changes of the body through sports perception, balance perception, touch, space perception, memory, thinking and imagination when finishing various sports techniques. In the process of pursuing muscularity and physical strength, people can truly experience the existence of active life vitality, maintain life vitality, which promotes students to explore the beauty of sports, and inspires students to love sports and love life. With the continuous practice of sports, students can develop various sports abilities, master various survival skills, and protect their own life safety. School physical education can promote the construction of students' good interpersonal relationships, promote the socialization of students and deepen students' understanding of life, so that they will respect life, show reverence to life and love life. Through overcoming difficulties, and controlling oneself as well as external environment in school physical education practice, students can cultivate positive and enterprising life attitude and tenacious will. Through cooperation and competition with others, students' understanding of the significance and value of self-existence can be improved.

\section{Ways to Implement Life Education with School Physical Education as Carrier}

School physical education has a rich carrier of physical education. Problems such as difficulties, setbacks, cooperation, competition, success, failure, rules, venues, opponents, teammates, judges, and fines and so on in physical education classes, after-school training, sunny recess, sports games, recess exercises and various individual competitions can all become entry points for students' life education. Physical education teaching takes reforming and improving the natural quality of life as its original value point, respects the original value 
intention based on life experience, cultivates students' social emotions that dare to bear, and enables life education to truly integrate into school physical education.

\subsection{Setting of school physical education goals with life education}

Attaching importance to life education should become a new educational concept and mission for teachers. However, up till now, the coverage of life education in our country is relatively low, with less than $30 \%$ of the provinces opening this subject. The development of life education is still slow, seriously lagging behind the demand for life education in our country. If universities truly want to integrate life education into school physical education, they should integrate it into the objectives of school physical education curriculum, change the educational concept, and raise the attention to life education from the perspective of ideology. When setting the goal of physical education curriculum, according to the age levels, the process of life education will gradually get involved into all stages of school physical education to form a complete system. At the same time, the curriculum content should be life-oriented and some practical methods and contents that show the main purpose of life education will be taught [3]. The education department should formulate corresponding policies to support and promote the integration of life education into school physical education curriculum.

\subsection{Contents of school physical education under the concept of life education}

3.2.1 Designing contents of school physical education to make students realize the existence of life in sports

The design of endurance exercise enables students to feel the physiological changes of the body, experience the "peak" and "second wind". PE teachers should consciously guide students to improve their kinestness, sense of equilibrium and organic sensation, feel the generation and elimination of fatigue, experience relaxation and energy after sports, so that students can truly perceive the existence of life. The content of muscle-building and body-shaping exercise is designed to guide students to dig out the content of life vitality in the process of sports so as to make them understand the form and connotation of vigorous life vitality. The sports skills taught to students are also survival and life-saving skills, such as swimming, martial arts, long distance running, climbing and so on, which plays an important role in protecting life. Through the design and implementation of the content of physical education, students can form positive, appreciative, affirmative, receptive, respectful, and life-loving positive life attitude that are optimistic, and tolerant in the practice of physical education.

Nowadays, swimming has been paid more and more attention and loved by people because of its unique characteristics of survival skill and the value of exercise and fitness. It has become one of the sports subjects selected by students in many provinces in the college entrance examination [4]. In the swimming teaching process, the school not only teaches students to swim, but also ensures students' personal safety. Since the meaning of life education is greater than its skill requirements, when designing the educational content, managers should follow the basic understanding rules of human beings, change the previous direct learning method, and design a reasonable learning mode of "survival and self-rescue--basic technology--exercise application--life-saving of others". Students can first take swimming as a game to eliminate the "fear of water", then practice "treading water" and "breaststroke" and carry out the technical learning of basic swimming strokes. After mastering it skillfully, students can carry out the learning of life-saving skills. In this way, students can perceive the existence of their own life from the initial goal of self-survival skills. Through further adaptation of body and mind, after learning and mastering the sports skill, students can also feel the fitness and heart-building values brought about by sports, and realize the improvement of their understanding of life brought by vitality. In the learning process and practical operation of life-saving skills, they can better experience the significance of life existence and help others while the social value is best embodied, which is the recreation of life and life value.

3.2.2 Carrying out group projects to enable students to correctly understand the orientation of social life

Students should correctly understand their roles in group projects. They should be educated to abide by the rules, adapt to site restrictions, establish suitable interpersonal relationships with teammates and opponents, correctly understand the relationship between cooperation and competition, correctly understand the meaning of winning and losing, and guide students to be right about winning and losing. They should understand fairness, learn to respect, understand friendship and excellence, continuously promote and deepen students' 
socialization degree, so that students can have a strong sense of life responsibility. Teachers should also cultivate students' life consciousness of respecting life and reverence for life, further stimulate their active, friendly and enthusiastic life motivation, and promote the continuous improvement and development of students' social life.

For example, the increasingly popular underwater diving project, which is closely linked with life, is one of the high-risk projects and is an experiential leisure skill project for life. Since it has the characteristics of leisure and entertainment, it is also gradually attracting more attention from colleges and universities. So the teaching of this course is attempted. Leisure diving requires at least 2 persons or more to carry out activities and the participants should assist each other in accomplishing diving goals, including diving plan, implementation process and problem solving. The activity mode embodied in the system of diving partners cultivates the sense of responsibility for human beings, which is also a kind of social responsibility. In the course of learning, the emphasis is placed on the cultivation of the sense of cooperation, which not only reflects self-leisure and entertainment experience in the activity, but also shows the characteristics of group activity. The consciousness of self-life protection and the consciousness of diving partner' life protection are integrated into one, forming a dual sense of life responsibility. Therefore, while students enjoy the relaxing and safely diving, this group project becomes meaningful in life education.

3.2.3 Develop situational teaching to cultivate students' understanding of spiritual life

Schools should carry out physical education teaching, training and competitions that are quite difficult to cultivate students' strong will, carry out highly-skilled technical teaching to promote and develop students' cognitive processes such as time perception, motion perception, and space perception. Through the education of prosperity and adversity, smoothness and setback in the process of sports practice, students can correctly understand the meaning and value of life and learn to control their emotions. Cultivating students' good personality through long-term sports practice can promote the development and perfection of students' spiritual life.

For example, sailboat project attracts people of different countries and races, different genders, different ages, and different social levels to participate with its unique charm. It is a vision integrating self-life with nature, and it is also full of self-challenge and challenge to nature. Its sailing route is complex, varied, thrilling and exciting [5]. Sailboat emphasizes perfect combination of the sense of responsibility and the cooperation of the team. For team members, every action greatly shows the team's sense of responsibility and teammate's trust. In sailboat competitions, if the basic rules are violated, one or two turns ( active self-punishment method ) should be carried out as punishment, which shows that in competitions one should understand the meaning of fairness, respect the opponent, and learn the friendship. Sailboard allows athletes to train or compete in harsh natural environment, which is a test of the ability of the sports and the corresponding endurance quality. Through sailboard teaching, students' will can be better trained, and various teaching scenarios can be set up, such as sailboard cars, sand beach simulation, calm water area practice, open water area auxiliary practice, etc. Judging the wind direction can test students' perception of space, how to quickly respond to practice, and how to adjust the speed of travel by controlling the angle of sailboard and wind by hand. In the process, the coordination needs to be carried out by the ups and downs of the center of gravity as well as the posture of the body. For students, it is a exercise with much skills and tests students' will and psychological quality during the practice in calm water area and open water area. The repeated attempts on sailboard are good processes of experiencing setback and education. They can not only experience the exciting feeling of speeding on the sea after mastering the technology, but also challenge the hard work in the beginning of the exercise. Therefore, students gain the sense of accomplishment and pride brought by the exercise, which also can get better exercise in their mind.

\subsection{Attaching importance to the intermediary function of teachers in life education and school education}

The implementer of life education in school physical education is the physical education teacher. Improving the understanding of the consistency between life education connotation and school physical education connotation and flexibly using the functions of various educational carriers in school physical education will help to play the role of school physical education in life education. While improving 
professional qualities, teachers should fully attach importance to and give full play to the importance of teachers in the education work, requiring every teacher to attach importance to the life of every student, care for their spiritual life, promote their social life, strictly implement the curriculum of physical education, and return the evaluation of courses to the most original purpose of education.

Health is an inevitable requirement to promote the all-round development of human beings. Under the guidance of the overall concept of "Massive Health", the health education function of life is highlighted. The goal of physical education in schools is to promote students' physical health and gain health in mental, psychological, social, environmental and moral aspects, and to promote them to develop good exercise habits. In the process of integrating life education into school education, P.E. teachers have played a more important role in training. During the implementation, the starting point is to cultivate students who have good moral quality, correct values, care for the lives of others, and help them develop the sense of social responsibility. Teachers are therefore required to improve their "teaching” ability [6]. Teachers' teaching ability directly affects the effect of teaching and largely determines the achievement of teaching goals. In order to have a better understanding of the connotation of life education, it is necessary to make it clear in explaining its consistency with the connotation of school physical education. In addition, teachers' demonstration ability is very important, especially in the study of physical education. In teaching self-protection and protecting others, it is necessary to convey correct life education so that students can understand their own social attributes and their own social values. At the same time, it is also necessary to actively promote their life values. At the same time, teachers should evaluate students objectively and impartially, so as to show the original purpose of "educating people”.

\subsection{Family, society and school working together to promote the development of life education}

The development of life education needs the joint promotion of families, society, schools and other aspects. The lack of any aspect may affect the process of life education. The relationship among families, society and schools must be handled well. The characteristics of social development and the advantages of school physical education must be integrated, to give full play to the ability of each part in the process of promoting life education. First of all, schools should give full play to the educational function of school physical education, establish the leading position of school institutions in the process of life education in the short term, use school's unique educational resources and educational methods, and play a guiding role in shaping concepts and conveying concepts so as to lay a good foundation for the initial establishment of life education. Secondly, schools should fully recognize the importance of family education in the process of life education and attach importance to the profound influence of the educational thoughts that exert a subtle influence on the formation of the joint force of life education. At the same time, schools should pay attention to creating a social environment that attaches great importance to life education and attract more social organizations and non-governmental educational institutions to participate in and invest in life education. Only through the joint promotion of the three parties can the development of life education be well and quickly promoted.

\section{Conclusion}

The promotion of life education in school physical education is a long way to go. The actual development dilemma, direction of public opinion and educational evaluation system of school physical education are all hindering the life education to a certain extent. Educators should face up to the difficulties and carry out their work with the aim of returning to the true nature of education. While discussing the significance of life value, they should pay close attention to the reform of school physical education curriculum in line with the educational concepts of "people-oriented" and "health first", so as to arouse the attention of more educational reformers and enable students to truly embark on the road of physical and mental health development. 


\section{References}

[1]. Ran Xuedong, Deng Chen Liang, "The triple attribute of life education and the reform of school physical education,” Journal of Shenyang Institute of Physical Education, vol. 32, pp. 67-69, May 2013. (In Chinese)

[2]. Ding Zhaoxiong, "Perspective on life education in physical education curriculum,” Journal of physical education, vol. 15, pp. 70-74, September 2008. (In Chinese)

[3]. Dan Yanfang, Li Xinke, Chen Qing, "Physical education: the return of the origin of life education," Journal of Wuhan Institute of Physical Education, vol. 42, pp. 78-81, April 2008. (In Chinese)

[4]. Duan Limei, Dai Guobin, "A new view of the logical starting point of physical education from the perspective of ‘whole person’ life education,” China Sport Science, vol. 35, pp. 78-82, July 2015. (In Chinese)

[5]. Wang Zipu, Sun Xueming, “The Construction of Life Safety Education System in School Physical Education in China,”Journal of physical education, vol. 19, pp. 93-95, September 2012. (In Chinese)

[6]. Wang Fan, Yang Xueqin, Mou Shaohua, et al., "The value of school sports education under the demand of life safety,” Journal of physical education, vol. 19, pp. 78-81, May 2012. (In Chinese) 